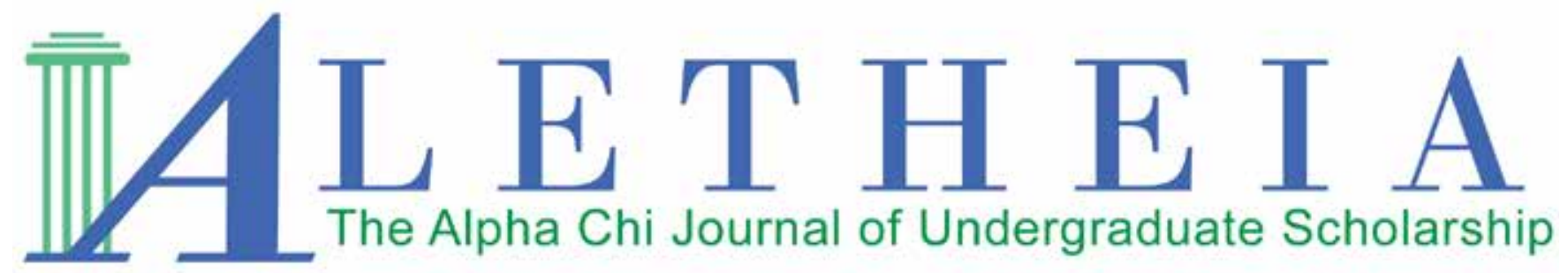

Volume 6 | Issue 2 | 2021

\title{
In Defense of the Art: How Literary Fiction Promotes Empathy
}

\author{
Courtney Cook
}

\author{
Abilene Christian University \\ Texas Psi Chapter
}

Vol. 6(2), 2021

Title: In Defense of the Art: How Literary Fiction Promotes Empathy

DOI: $10.21081 / \mathrm{ax} 0303$

ISSN: 2381-800X

Keywords: empathy, morality, fiction, perspective

This work is licensed under a Creative Commons Attribution 4.0 International License.

Author contact information is available from tlindblom@alphachihonor.org or kvosevich@alphachihonor.org

\section{Aletheia-The Alpha Chi Journal of Undergraduate Scholarship}

- This publication is an online, peer-reviewed, interdisciplinary undergraduate journal, whose mission is to promote high quality research and scholarship among undergraduates by showcasing exemplary work.

- Submissions can be in any basic or applied field of study, including the physical and life sciences, the social sciences, the humanities, education, engineering, and the arts.

- Publication in Aletheia will recognize students who excel academically and foster mentor/mentee relationships between faculty and students.

- In keeping with the strong tradition of student involvement in all levels of Alpha Chi, the journal will also provide a forum for students to become actively involved in the writing, peer review, and publication process.

- More information can be found at www.alphachihonor.org/aletheia. Questions to the editors may be directed to tlindblom@alphachihonor.org or kvosevich@alphachihonor.org.

Alpha Chi National College Honor Society invites to membership juniors, seniors, and graduate students from all disciplines in the top ten percent of their classes. Active on nearly 300 campuses nationwide, chapters induct approximately 10,000 students annually. Since the Society's founding in 1922, Alpha Chi members have dedicated themselves to "making scholarship effective for good." Alpha Chi is a member in good standing of the Association of College Honor Societies, the only national accrediting body for collegiate honor societies. A college seeking a chapter must grant baccalaureate degrees, be regionally accredited, and be a not for profit institution. 


\title{
In Defense of the Art: How Literary Fiction Promotes Empathy \\ Courtney Cook
}

\author{
Abilene Christian University \\ Texas Psi Chapter
}

\begin{abstract}
This article draws on the research of psychologists and educational theorists to determine the relationship fiction exposure has on the development of empathy and moral agency in readers. A definition of moral agency, empathetic simulations, and moral laboratory as presented by researchers and psychologists Black and Barnes, Mar and Oatley, and Albert Bandura is first explored in this paper. These theories on moral and empathetic development are then applied to Moshin Hamid's Exit West, a refugee account, in order to fully explore how readers engage in empathy as they read fictional stories. This article concludes that fiction encourages empathetic development and that fiction readers frequently engage in organic empathetic simulations.
\end{abstract}

Keywords: empathy, morality, fiction, perspective 
Psychologists Jessica E. Black and Jennifer L. Barnes assert that literary fiction has long been revered for its ability to "exert moral influence on readers" (149). Black and Barnes are supported in this assertion by the work of educational theorist Albert Bandura and psychologists Raymond A. Mar and Keith Oatley, who have explored how fiction readers use literature as a tool to establish a greater sense of morality. Fiction reading has long supplemented medical education as a pathway to empathy in patient care, and reading groups are being adopted into the corporate world with rapid speed to increase understanding between managers and employees (Thexton et al. 84). In these examples, literature is understood to be inherently valuable in its unique ability to portray various perspectives in purposeful, empathy-inducing ways. After defining the most prominent theories on the connection between fiction and empathy, this paper will explore the ways in which Mohsin Hamid's Exit West allows readers to meaningfully engage with foreign worldviews and respond empathetically to the plight of the human experience.

\section{Connections Between Literary Fiction and Empathy Development}

Several theories and research methodologies have contributed to the suggestion that literature can lead to empathetic outlooks in readers. Black and Barnes conducted a series of studies on young adult subjects to explore whether fiction operates as a "moral laboratory"-a space for moral convictions to grow stronger - or if fiction inspires "moral boundary corrosion," in which readers come to understand the immorality of fictional characters as acceptable behavior (150). Although numerous studies have been conducted on empathy development in young adolescents, Black and Barnes rely on the theories of Albert Bandura, whose work is continually referenced in this paper, to guide their research. This study revealed that readers most often engage with fiction as a moral laboratory, although readers are also more inclined to extend greater moral permissibility to the characters they encounter in fiction (157). While these two conclusions may appear contradictory, it follows that readers whose empathetic impulses are strengthened in their reading of fiction may be more inclined to empathize with these fictional characters and extend grace to their moral failings as a result.
Like the study published by Black and Barnes, Mar and Oatley's article focuses solely on the moral construct of empathetic behavior and theorizes that fiction allows readers to engage in "empathetic simulations" (173). As readers engage with fictional characters and experience their emotions, they can apply their own social understandings to these fictional worlds and relate to the plight of each character. Eventually, critical readers learn to interact with fiction in ways that "facilitate the understanding of others who are different from [themselves] and can augment [their] capacity for empathy and social inference" (Mar and Oatley 173). Engaging in these fictional simulations has real-life implications for readers, as their capacity to empathize and relate to others grows exponentially. This theory of empathetic simulation is closely related to theory of mind, which posits that individuals can reason about the beliefs and intentions of others and, thus, understand their behaviors (Thexton et al. 84). Readers rely on theory of mind to understand both the gravity of positions fictional characters encounter and the decisions each character makes in the face of adversity. Both empathetic simulations and theory of mind are essential to the engaged fiction reader's ability to empathize with fictional characters and eventually apply this empathy to real-life social situations.

Bandura's theory of social cognition gives greater substance to the consideration of literary fiction's ability to create empathetic people. The social cognitive theory suggests that fiction consumers view fictional characters as models for moral ideals, exemplifying morally relevant behavior that readers will be inclined to replicate (Black and Barnes 149-150). Bandura also argues that fiction establishes a sense of moral agency in readers, allowing them to develop a greater understanding of which behaviors are socially acceptable and which are not (qtd. in Black and Barnes 150-151). Without this sense of moral agency, people are more likely to avoid moral responsibility through such mediums as dehumanization, a mentality that denies humanity to those whose worldviews or ways of living disagree with the reader (Black and Barnes 150). Engaged reading of literary fiction avoids this drastic degradation of humanity, as readers are actively building moral agency that allows them to extend humanity and human decency to fictional characters and real people alike.

It is also important to note that highly engaged fiction readers experience changes in perspective that result in empathetic behavior, whereas readers who are 
not engaged when reading fiction have empathy scores far below those of nonfiction readers (Black and Barnes 150). Literary engagement makes all the difference in encouraging empathetic behavior. To develop empathy, readers must approach literary fiction critically, bringing their own understandings of and experiences within the world to each reading. Critical engagement with literary fiction through thoughtful conversation that draws on both the text and personal experiences enhances the process of empathy development. Engaging with literary fiction through conversation and critical analysis allows readers to think for themselves and come to concrete conclusions about how people, in fiction and in flesh, should be regarded.

The theories regarding empathy and moral development that have been outlined in this section will be applied directly to Mohsin Hamid's Exit West to exemplify the opportunities for empathetic growth available to engaged and critical readers. Although many analyses of empathy development in fiction adopt a reader response framework, this paper approaches such development from a critical analysis of Exit West to illustrate how thoughtful engagement with fiction can allow readers to respond empathetically to the characters they encounter.

\section{Application to Mohsin Hamid's Exit West}

Although the refugee narrative in Mohsin Hamid's Exit West is drastically different from what many Americans have grown to expect from the world, this novel provides engaged readers with many opportunities to understand the plight of refugees, recognize their inherent humanity, and empathize with the characters and their positions in the world as a result. In an interview with The Nation following the release of Exit West, Hamid argues that "if we can recognize the universality of the migration experience and the universality of the refugee experience ... then the space for empathy opens up" (Chandler and Hamid). This ideology guides the plot of Exit West, as readers are immediately encouraged to identify with Nadia and Saeed, the only named characters in a sea of unnamed people and places. Although there are several suggestions that their homeland is in the Middle East, the specific country is intentionally left unnamed, encouraging, as Michael Perfect states, "readers to insert [the names] of their own" countries and cities in its absence, thus facilitating "readerly identification with" these foreign lands from the first page (190). This readerly identification is exactly what Bandura describes in his social cognitive theory, suggesting that readers who can personally identify with and relate to fictional characters will be more likely to empathize with the adversity each character faces.

If the suggestion that readers learn to understand and identify with Nadia and Saeed simply by the implied universality of a nameless city is unconvincing, consider the following excerpt from the second paragraph of the novel as further proof:

It might seem odd that in cities teetering at the edge of the abyss young people still go to class ... but that is the way of things, with cities as with life, for one moment we are pottering about errands as usual and the next we are dying, and our eternally impending ending does not put a stop to our transient beginnings and middles until the instant when it does. (Hamid 3-4)

This musing on the human tendency to continue routine life in the face of adversity is perhaps more timely and more relevant than Hamid could have foreseen. The intersection of literary fiction and our own positions within real-world contexts creates natural opportunities for expressions of empathy. In the current context of the COVID-19 outbreak, this passage creates opportunities for readers to engage in an empathetic simulation simply because the environment described in this passage mirrors an environment familiar to the reader. As an undergraduate student who continued to participate in classes via Zoom during the pandemic, I found that this passage spoke to my own experience and made the position of Nadia and Saeed instantly relatable. Beyond the college campus, people continue the mundane routines of their pre-pandemic lives while watching anxiously as the ongoing pandemic places ever-increasing stress on the integral structures of their communities. Critical readings of works of fiction allow us more natural opportunities to engage theory of mind and understand the plight of the characters we follow throughout the novel. Although unintentional on Hamid's part, this novel's opening pages echo the current state in which people around the world find themselves, immediately allowing readers to better understand Nadia and Saeed's world and empathize with their experiences.

The opening chapters progress in this same vein, allowing readers to understand and relate to Nadia 
and Saeed through the universally understandable descriptions of their beginning relationship. Descriptions exploring the awkward and uncomfortable beginnings that always accompany budding romances are intentionally designed to make Nadia and Saeed understandable and relatable characters. This society looks different from American society-in America, it is not rare to meet women who live alone, and it is certainly not common to hide a romantic relationship in fear of governmental reprimand-but the relationship itself blooms just as one would expect from two twenty-somethings. This, of course, is by design: readers are expected to relate to Nadia and Saeed and understand their awkward navigation through these new relationships. As a result, readers are inclined to identify with Nadia and Saeed, literally putting themselves in the shoes of these characters and viscerally experiencing the same emotions that Nadia and Saeed experience. As Bandura's theory of social cognition would suggest, in these opening chapters it is essential for readers to identify with Nadia and Saeed when they are the most "relatable" in their positions as citizens, not alienated refugees (qtd. in Black and Barnes 150-151).

To add depth to each reader's understanding of the refugee, Hamid includes several depictions of the refugees who live in the margins of Nadia and Saeed's homeland. These refugees are described in terms that make it clear that they are an unwanted afterthought for both Nadia and Saeed, as exemplified in one of the earliest descriptions of a refugee camp: "Refugees had occupied many of the open places in the city, pitching tents in the green belts between roads, erecting lean-tos next to the boundary walls of houses, sleeping rough on pavements and in the margins of streets . . . Saeed and Nadia had to be careful when making turns not to run over an outstretched arm or leg" (Hamid 23). The makeshift shelters of the refugees are found "between roads" and "in the margins of the streets," making clear the marginal existence of refugees in Nadia and Saeed's homeland (Perfect 191). This passage works hard to draw a clear distinction between the plight of "them" and the security of "us" (Perfect 191). Because readers see themselves reflected in Nadia and Saeed, they are quick to dismiss the marginal refugees, just as Nadia and Saeed do. Of course, Nadia and Saeed try to be mindful of the refugees, swerving away from "an outstretched arm or leg," just barely regarding these people with human decency. The refugees' inherent humanity is only marginally recognized by Nadia and Saeed, who reduce the refugees to mere body parts that serve as obstacles to otherwise smooth driving (Perfect 191). Worse than extending only marginal humanity to these refugees is the air of self-congratulation shared between Nadia and Saeed as they successfully avoid hitting these people with their cars and motorcycles.

Worst of all, however, is the engaged reader's realization that the marginalization Nadia and Saeed unwittingly subject these refugees to must be the same attitude readers adopt towards refugees, as they are inextricably aligned with the attitudes of Nadia and Saeed through Hamid's specific focus on their perspectives. Passages like this encourage readers to realize that they are empathizing only with characters who reflect their insensitive perspectives on refugees. Perhaps readers will not yet reach this realization, and it will only be after encountering Nadia and Saeed - and themselves, by proxy - as refugees that they learn to extend empathy to the plight of the refugee. In any case, this division between Nadia and Saeed and the refugees is intentional, as Hamid believes there is a concerning lack of empathy regarding the current refugee crisis, and, as Perfect reports, he seeks to "achieve readerly empathy [for] two characters who become refugees" by first "[beginning] with those two characters being themselves unable to empathize with refugees" (191). This simulates the position of many readers as they begin the same journey through reading this novel.

Readers continue their journey of empathetic development with Nadia and Saeed as tensions and civil unrest begin to rise in their homeland and hinder the development of their relationship. This disruption is best illustrated in the national power outage that "[deprives Nadia and Saeed] of the portals to each other and to the world" (Hamid 57). This is the first time that Nadia and Saeed are left feeling isolated and estranged from the once-familiar world around them, an ominous foreshadowing of the estrangement they are to encounter as refugees later in the book. In this incident, panic grows for both Nadia and Saeed as she prepares for disaster by collecting as much food as she's allowed, and he searches desperately for a way to reconnect with her after cell phone lines have been severed. This event deviates drastically from the budding romance readers have been engaged in thus far, and readers may need to recalibrate their understanding of Nadia and Saeed by engaging in theory of mind. Readers have already grown to identify 
with these two characters, so applying theory of mind to their new circumstances should not be difficult - readers need only to consider how they would likely feel and react in the same situation to better understand Nadia and Saeed's reactions. Because critical readers have likely identified with the familiar worldview Hamid presents in the beginning chapters of Exit West, they will be able to engage in this foreign worldview with Nadia and Saeed as they experience it for the first time. This understanding continues to allow readers to engage theory of mind as they enter the perspective of refugees. Such engagement provides empathetic simulations that allow readers to expand their sense of moral agency if they are willing.

Nadia and Saeed's isolated and estranged future as refugees is set on course by a nationwide power outage. In the months that follow, Saeed loses his mother to urban violence, which grows so turbulent that Nadia and Saeed fear even to step outside on the patio of their own home. In his bereavement, Saeed begrudgingly agrees to leave behind his beloved homeland and his parents in search of a life of relative safety as a refugee. Exiting through a magical portal to this promised refuge, Saeed and Nadia shut the door on their lives as state-supported citizens and begin a new life as refugees. Already, the reader begins to feel differently about the depiction of the refugee, as those who have engaged theory of mind see themselves reflected in Nadia and Saeed, who are beginning to adjust to this new position in life. No longer do refugees appear only marginally human and deserving of only the most basic human decency; according to Bandura's theory of mind, these readers can understand at least these two refugees to be complex and multi-dimensional characters with all the same capacity for human feeling as naturalized citizens.

Interestingly, because Nadia and Saeed have been reduced to the marginal existence all refugees are subjected to, they begin to lose sight of their own humanity. It is surreal for readers to watch as Nadia and Saeed, previous bestowers of pity and mercy to the refugees in their homeland, beg for pity and mercy of their own. Instead of worrying about the survival of their relationship and their success in school, becoming refugees reduces Nadia and Saeed to worrying about their physical survival in foreign and hostile lands. Readers who have learned to engage theory of mind and have seen themselves reflected in Nadia and Saeed can now understand the plight of these characters as they spend all their ener- gy focused on their survival. No longer does the refugee experience appear foreign and unfamiliar to readers who have engaged theory of mind, as they too are able to engage in an empathetic simulation of the worries that surround Nadia and Saeed's new position as refugees.

Luckily for them, there are helpful characters interspersed throughout their refugee journey rooting for them, empathizing with them, and working to ensure better futures and greater safety for them. The woman Nadia and Saeed meet at the clinic in Mykonos is one such helpful character. She connects with Nadia and Saeed by recognizing their humanity and securing their passage to refuge in a safer location. The fact that this woman is the first person to treat Nadia and Saeed like human beings after they become refugees continues to point out the frequent, careless marginalization of refugees. This volunteer also presents a new understanding of empathy that is in accordance with Black and Barnes' suggestion that literature acts as a moral laboratory; her show of empathy-turned-action for Nadia and Saeed exemplifies how to effectively extend empathy to those in need in real-world situations. This understanding of empathy differs from the active participation demanded by social cognitive theory and empathy simulation, but observing empathy in action is also an integral part of becoming a good practitioner of empathy.

As their refugee journey drags on and Nadia and Saeed become more wary, they begin to develop their own, often contradictory, perceptions of what it means to be both human and refugee. Saeed seeks refuge in groups of people who look and act and eat like him, so uncomfortable in the inter-cultural mixing of his first place of refuge in London that he is determined to give up a private room with Nadia and instead sleep on the floor next to "[his] own kind" (Hamid 153). Saeed longs to maintain tangible connections to his native culture and the people with whom he identifies, whereas Nadia is ready to sever all cultural ties to "the country [she] used to be from" (Hamid 153). Nadia and Saeed's conflicting needs to relate and connect with other people result in two different, yet both poignant, reflections on what it means to be a human facing adversity. These reflections are meant to help readers understand and identify with both Nadia and Saeed as the chasm between them slowly grows deeper.

Nadia discovers how she finds meaningful connections to her own humanity after going to London and taking advantage of the available shower across from 
her bedroom. Saeed is upset with her for taking so long to wash the grime of travel off her body and her clothes, but for Nadia, this shower is "not about frivolity," but "the essential, about being human, living as a human being" (Hamid 126). This mundane act that many readers neglect to appreciate - or even begrudge - is about much more than just getting clean. Readers who have engaged their theory of mind and learned to identify with Nadia over the course of the novel understand that true connection to humanity is having the freedom to participate in these mundane routines. This freedom to choose is established on the novel's first page, when Nadia and Saeed are attending school amid urban warfare and civil unrest. To become a marginalized refugee is to be stripped of small freedoms, and to reconvene such mundane activities is to be welcomed back, if only temporarily, into the world of fully recognized humanity.

Saeed seems to find meaningful connection to his own humanity not through the small, everyday freedoms that Nadia relishes, but in community with his cultural heritage. In one of the most heart-wrenching paragraphs of the entire novel, Saeed reflects on his lingering connections to an otherwise completely lost family:

When he prayed he touched his parents, who could not otherwise be touched, and he touched a feeling that we are all children who lose our parents, all of us ... and we too will all be lost by those who come after us and love us, and this loss unites humanity, unites every human being ... the heartache we each carry and yet too often refuse to acknowledge in one another. (Hamid 202-203)

Saeed muses that what unites humanity is the universal experience of loss and subsequent heartache. Life is about the business of alienating people from their cultural roots and their families through death and other tragic losses, and yet this alienation is universally experienced by all human beings. To ignore the inevitable burdens of heartache carried by every fellow human being is to deny them humanity. Readers realize that Saeed's insistence that he interact primarily with people from his cultural heritage is not an effort to deny humanity to other cultures but to help him maintain his already wavering connection with his own humanity.

Hamid's Exit West supports both Black and Barnes' theory that literary fiction invites readers to use literature as a moral laboratory and Mar and Oatley's theory that fiction facilitates empathetic simulations to be completely explored. Through Nadia and Saeed's journey from naturalized citizens who have a secured place in society to the wandering refugees they eventually become, readers can engage in empathetic simulations that inevitably allow them to better understand the plight of these two characters. When one also considers how Bandura's theory of mind explores how readers take their newfound understanding of Nadia and Saeed's positions as refugees and place themselves in the same situation, it becomes clear that literary fiction such as Exit West provides readers with unique avenues for expressions of empathy.

In essence, empathy is an exercise in extending humanity to those who do not immediately resemble our own understanding of what a person ought to be. Nadia and Saeed's reflections on their connection to humanity and the desire for recognition and acceptance that all people have create essential pathways to empathetic expressions in readers as a result of Hamid's focus on Nadia and Saeed's refugee experience. Exit West is one of many examples of fiction that carefully considers the plight of the human condition, allowing readers to emerge from their reading with a new or more fully developed understanding of how to extend humanity to all people. Without the medium of literature to foster these simulations of empathy, there would be far fewer people able to understand the plight of human existence that differs from their own. 


\section{Works Cited}

Black, Jessica E., and Jennifer L. Barnes. "Fiction and Morality: Investigating the Associations Between Reading Exposure, Empathy, Morality, and Moral Judgment." Psychology of Popular Media, vol. 10, no. 2, April 2021, pp. 149-64. EBSCOhost, doi:10.1037/ppm0000281

Chandler, Caitlin L., and Mohsin Hamid. "We Are All Refugees: A Conversation with Mohsin Hamid." The Nation, 30 Oct. 2017, www.thenation.com/ article/archive/we-are-all-refugees-a-conversationwith-mohsin-hamid/.

Hamid, Mohsin. Exit West: A Novel. Riverhead Books, 2017.

Mar, Raymond A., and Keith Oatley. "The Function of Fiction Is the Abstraction and Simulation of Social Experience." Perspectives on Psychological Science, vol. 3, 1 May 2008, pp. 173-92. EBSCOhost, doi:10.1111/j.1745-6924.2008.00073.x.

Perfect, Michael. “'Black holes in the fabric of the nation': Refugees in Mohsin Hamid's Exit West." Journal for Cultural Research, vol. 23, no. 2, 2019, pp. 187-201. EBSCOhost, doi: 10.1080/14797585.2019.1665896

Thexton, Todd, et al. "Learning Empathy Through Literature." Culture and Organization, vol. 25, no. 2, 2019, pp. 83-90. EBSCOhost, doi:10.1080/147595

51.2019 .1569339 